\title{
16S rDNA PCR-DGGE and sequencing in the diagnosis of neonatal late-onset septicemia
}

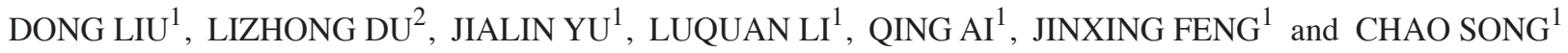 \\ ${ }^{1}$ Department of Neonatology, Children's Hospital, Chongqing Medical University, \\ Ministry of Education Key Laboratory of Child Development and Disorders, Key Laboratory of \\ Pediatrics in Chongqing and Chongqing International Science and Technology Cooperation Center \\ for Child Development and Disorders, Chongqing 400014; ${ }^{2}$ Department of Neonatology, \\ The Children's Hospital Zhejiang University School of Medicine, \\ Hangzhou, Zhejiang 310003, P.R. China
}

Received September 25, 2014; Accepted July 10, 2015

DOI: $10.3892 / \mathrm{mmr} .2015 .4131$

\begin{abstract}
The 16S rDNA polymerase chain reaction (PCR)-denaturing gradient gel electrophoresis (DGGE) and sequencing method has been demonstrated to be valuable in detecting pathogens in the blood of patients suffering from fever or neutropenia. However, its use in the diagnosis of neonatal late-onset septicemia (LOS) has not yet been reported. The aim of the present study was to investigate the efficiency of this method in detection of the type of bacterial infection in neonatal LOS. Blood specimens from 60 neonates in whom LOS was suspected were collected. Fourteen culture positive blood samples and 24 spiked 'infected' blood samples were analyzed by the $16 \mathrm{~S}$ rDNA PCR-DGGE and sequencing method or by pathogen-specific PCR. Only in 5 of the 14 cases did the results of 16S rDNA PCR-DGGE and sequencing match with the results of blood culturing. In the other 9 cases, the blood culture failed to detect bacteria, such as Neisseria sp. and Moraxella sp., which were detected by 16S rDNA PCR-DGGE and sequencing. Furthermore, the 16S rDNA PCR-DGGE and sequencing failed to detect blood culture-proven bacteria, such as Klebsiella pneumonia. A competitive inhibitory effect in $16 \mathrm{~S}$ rDNA PCR amplification may lead to the discrepancy between pathogen-specific PCR and spiked 'infected' blood samples. When a certain species
\end{abstract}

Correspondence to: Professor Jialin Yu, Department of Neonatology, Children's Hospital, Chongqing Medical University, Ministry of Education Key Laboratory of Child Development and Disorders, Key Laboratory of Pediatrics in Chongqing and Chongqing International Science and Technology Cooperation Center for Child Development and Disorders, 136 Zhongshan 2nd Road, Chongqing 400014, P.R. China

E-mail: yujialin486486@hotmail.com

Key words: neonate, late-onset septicemia, competitive inhibitory effect, 16S rDNA polymerase chain reaction, denaturing gradient gel electrophoresis of bacteria was detected by 16S rDNA PCR, the competitive inhibitory effect presented a higher sensitivity in detecting this species in the blood samples that contained bacterial DNA only from this species compared with the blood samples that were blended with other bacterial DNAs. In conclusion, $16 \mathrm{~S}$ rDNA PCR-DGGE and sequencing can detect a more comprehensive spectrum of pathogens than blood culture. However, the competitive inhibitory effect, which may lead to false negative results should be taken into consideration when the $16 \mathrm{~S}$ rDNA PCR-DGGE and sequencing method is applied to the diagnosis of neonatal LOS.

\section{Introduction}

Neonatal late-onset septicemia (LOS) is a common complication of infants under prolonged hospitalization in the neonatal intensive care unit (1). LOS occurs in $\sim 10 \%$ of all neonates in neonatal intensive care units and up to $21 \%$ of very low birth weight infants experience an episode of $\operatorname{LOS}(2,3)$. Fast and accurate diagnosis is important for reduction of the mortality of LOS. Although blood culture remains to be the gold standard in the diagnosis of bacterial bloodstream infections, this method has certain limitations, such as a long waiting time for results (at least $48 \mathrm{~h}$ ), poor sensitivity (10-20\%) in detecting fastidious microbes, and the use of antibiotics before blood specimens are drawn, which may affect the results obtained from the blood culture $(4,5)$. In addition, the blood culture method is flawed in detection of polymicrobial infection $(5,6)$.

The 16S rDNA polymerase chain reaction (PCR), based on the amplification of 16S rDNA in bacteria, is fast with high sensitivity and can fully detect the whole bacterial spectrum in the experimental samples (7). In combination with denaturing gradient gel electrophoresis (DGGE) and sequencing, 16S rDNA PCR has been used to detect the pathogens in the blood of patients suffering from fever or neutropenia (8). However, the use of $16 \mathrm{~S}$ rDNA PCR in the diagnosis of neonatal LOS has not yet been reported. The aim of the present study was to investigate the efficiency of $16 \mathrm{~S}$ rDNA PCR-DGGE and sequencing in the detection of bacteria in neonatal LOS. 


\section{Materials and methods}

The study protocol was approved by the Institutional Review Board of the Children's Hospital, Chongqing Medical University (Chongqing, China). Informed written consent was obtained from the guardians of the enrolled neonates.

Diagnostic criteria. Signs and symptoms suggestive of clinical sepsis were: Unstable temperature, lethargy, irritability, gastrointestinal dysfunction with milk intolerance, vomiting, abdominal distension or bloody stool, respiratory dysfunction, sudden increase in respiratory rate or persistent tachypnoea, and tachycardia or bradycardia. These signs and symptoms were described in detail in a previous study (9).

Sample collection. From January to May 2012, 60 neonates who were suspected of neonatal septicemia according to the above diagnostic criteria in the Department of Neonatology, Children's Hospital of Chongqing Medical University were enrolled in the present study. Paired blood samples were collected after careful skin disinfection and sent for blood culture and molecular analysis. Blood samples from 10 neonates diagnosed with jaundice (caused by $\mathrm{ABO}$ hemolytic disease, without any evidence of infection or antibiotic treatment) were collected and served as negative controls. Venous blood ( $3 \mathrm{ml}$ ) was collected, of which $1 \mathrm{ml}$ was inoculated in the corresponding culture bottles for aerobic blood culture in the BACTEC 9120 system (BD Diagnostics, Bergen, NJ, USA), and another $1 \mathrm{ml}$ was used for anaerobic blood culture in the BacT/Alert system (BioMérieux, Marcy-l'Etoile, France). The remaining $1 \mathrm{ml}$ venous blood was collected in a sterile blood collection tube containing EDTA (Shanghai Kehua Bio-engineering, Shanghai, China) and stored at $-70^{\circ} \mathrm{C}$ until molecular processing.

DNA extraction. DNA extraction was performed according to the manufacturer's instructions using the QIAamp DNA Blood Mini kit (Qiagen, Hilden, Germany) with sterile water as a negative control. The blood samples were frozen, thawed for 3 cycles, and incubated at $37^{\circ} \mathrm{C}$ for $1 \mathrm{~h}$ with mixing every $20 \mathrm{~min}$ followed by the addition of $180 \mu \mathrm{l}(40 \mathrm{mg} / \mathrm{ml})$ lysozyme (Sigma-Aldrich, St. Louis, MO, USA). All DNA extraction reagents except the lysozyme solution were filtered through a $0.22-\mu \mathrm{m}$ filter prior to bacterial DNA extraction. Whole genomic DNA (100 ml), including bacterial genomic DNA, was dissolved in buffer AE $(10 \mathrm{mM}$ Tris $\cdot \mathrm{Cl}, 0.5 \mathrm{mM}$ EDTA, $\mathrm{pH}$ 9.0) and stored at $-20^{\circ} \mathrm{C}$. PCR amplification was performed using a PCR amplifier (Eppendorf, Humburg, Germany), with previously described thermocycling conditions (8).

16S rDNA nested PCR amplification. Primers for amplification of the variable region of $16 \mathrm{~S}$ rDNA for reaction 1 were as follows: B5, 5'-TCAGATTGAACGCTGGCGGC-3' and B4, 5'-TATTACCGCGGCTGCTGGCA-3' (8). The amplified 493-bp products from reaction 1 were then amplified in reaction 2 with primers P2 (5'-CCTACGGGAGGCAGCAG-3') and P3 (5'-ATTACCGCGGCTGCTGG-3') starting from nucleotide 341 and 534 of the 16S rDNA, respectively (8). A 40-bp GC clamp was attached to the 5 ' end of the $\mathrm{P} 2$ primer to prevent complete separation of PCR amplicons during DGGE analysis. The sterile water was filtered through a $0.22-\mu \mathrm{m}$ filter to avoid possible contamination. The PCR mixture of the first amplification was adjusted to a final volume of $25 \mu \mathrm{l}$ with sterile water after $12.5 \mu \mathrm{l}$ of Premix Taq (Takara Bio Inc., Otsu, Japan), $0.5 \mu \mathrm{l}$ each primer $(10 \mu \mathrm{M})$, and $5 \mu$ l DNA template were added. The PCR mixture of the second amplification was adjusted to a final volume of $50 \mu \mathrm{l}$ with sterile water after $1 \mu \mathrm{l}$ of PCR product from the first amplification, $25 \mu \mathrm{l}$ Premix Taq (Takara Bio Inc.), and $1 \mu \mathrm{l}$ each primer $(10 \mu \mathrm{M})$ were added, with sterile water used as a negative control.

$D G G E$ analysis. DGGE analysis was performed using the Dcode Universal Mutation system (Bio-Rad, Hercules, CA, USA) following the manufacturer's instructions. The products from PCR amplification were first electrophoresed on a $2 \%$ (wt/vol) agarose gel and stained with $4 \mathrm{~S}$ nucleic acid (Sangon Biotech Co. Ltd., Shanghai, China). Only samples with visible target bands were adopted for further DGGE analysis. Electrophoresis was performed on $8 \%$ polyacrylamide gels with a denaturing gradient ranging from 35 to $65 \%$ in $1 \mathrm{X}$ TAE buffer (0.04 M Tris-acetate, 0.001 M EDTA; pH 8.0) at $85 \mathrm{~V}$ and $60^{\circ} \mathrm{C}$ for $16 \mathrm{~h}$. Then the gels were incubated in $1 \mathrm{X}$ TAE buffer containing SYBR Green I (Biotech, Beijing, China) for 30 min and scanned using a Benchtop 3UV Transilluminator (UVP, Inc., Upland, CA, USA). Each visible band was excised from the DGGE polyacrylamide gels, placed in $30 \mu \mathrm{l}$ of sterile water, and incubated at $4^{\circ} \mathrm{C}$ overnight. PCR-DGGE analysis of each sample was repeated twice.

TA cloning. DNA recovered from excised DGGE bands was amplified by PCR as described previously (10), and the PCR products were electrophoresed on a $2 \%$ agar gel and purified using the Gel DNA Extraction kit (Takara Bio Inc.). The purified PCR products $(2 \mathrm{ml})$ were used to perform TA cloning using the pMD 18-T Vector kit (Takara Bio Inc.) according to the manufacturer's instructions. Then the pMD 18-T plasmids containing the PCR amplicons were transformed to Escherichia coli DH5 $\alpha$-competent cells (TIANGEN Biotech (Beijing), Co., Ltd., Beijing, China) and cultured on ampicillin-resistant Luria-Bertani (LB) broth at $37^{\circ} \mathrm{C}$ overnight.

Confirmation of the cloned DNAs by colony PCR. Clones on ampicillin-resistant LB media were collected and blended in $10 \mu \mathrm{l}$ sterile water. Then colony PCR was performed to confirm the cloned DNAs using primers M13-RV (5'-CAGGAAACAGCTATGAC-3') and M13-M3 (5'-GTAAAACGACGGCCAGT-3'). The PCR mixture containing $1 \mu \mathrm{l}$ template (the monoclone blended in sterile water), $1 \mu \mathrm{l}$ of each primer $(10 \mu \mathrm{M})$, and $12.5 \mu \mathrm{l}$ Premix Taq (Takara Bio Inc.) was adjusted to a final volume of $25 \mu \mathrm{l}$ with sterile water. The PCR mixture was first incubated at $94^{\circ} \mathrm{C}$ for $7 \mathrm{~min}$ followed by a total of 30 cycles of $30 \mathrm{sec}$ at $94^{\circ} \mathrm{C}, 30 \mathrm{sec}$ at $60^{\circ} \mathrm{C}$, and $30 \mathrm{sec}$ at $72^{\circ} \mathrm{C}$, with a final step at $72^{\circ} \mathrm{C}$ for $5 \mathrm{~min}$. The length of each amplicon was confirmed by agarose gel electrophoresis.

Sequencing of PCR products. The sequencing of the PCR products was performed on an ABI 3730xl DNA Analyzer with M13+(-47) primers and BigDye terminator v3.1 (Applied Biosystems, USA) at Sangon Biotech (Shanghai, China), 
Table I. Comparison of sequencing results of blood culture.

Identified bacterial species

Patient
Blood culture
16S rDNA PCR-denaturing gradient gel electrophoresis and sequencing method

\begin{tabular}{|c|c|c|}
\hline 1 & Klebsiella pneumoniae & $\begin{array}{l}\text { Neisseria } \mathrm{sp} ., \text { Moraxella sp., } \\
\text { Enterobacter sp., Micrococcus sp. }\end{array}$ \\
\hline 2 & Klebsiella pneumoniae & $\begin{array}{l}\text { Moraxella sp., Acinetobacter sp., } \\
\text { Bacillus sp., Aeromonas sp. }\end{array}$ \\
\hline 3 & Escherichia coli & Escherichia coli ${ }^{\mathrm{a}}$, Vibrio sp. \\
\hline 4 & Group B Streptococcus & $\begin{array}{l}\text { Stenotrophomonas sp., } \\
\text { Acinetobacter sp., sphingobacterium }\end{array}$ \\
\hline 5 & Enterococcus faecalis & $\begin{array}{l}\text { Micrococcus sp., Klebsiella sp., } \\
\text { Enterobacter sp., Acinetobacter sp. }\end{array}$ \\
\hline 6 & Serratia marcescens & Acinetobacter sp., Enterobacter sp. \\
\hline 7 & Staphylococcus epidermidis & $\begin{array}{l}\text { Staphylococcus epidermidis, } \\
\text { Bacillus sp., Halomonas sp., } \\
\text { Propionibacterium sp. }\end{array}$ \\
\hline 8 & Staphylococcus aureus & $\begin{array}{l}\text { Acinetobacter sp., Klebsiella sp., } \\
\text { Enterobacter sp., Micrococcus sp. }\end{array}$ \\
\hline 9 & $\begin{array}{l}\text { Enterobacter cloacae, Klebsiella } \\
\text { pneumoniae }\end{array}$ & $\begin{array}{l}\text { Klebsiella sp., Enterobacter sp., } \\
\text { Acinetobacter } \mathrm{sp} . \\
\text { Corynebacterium } \mathrm{sp} .\end{array}$ \\
\hline 10 & $\begin{array}{l}\text { Enterococcus faecium, Staphylococcus } \\
\text { haemolyticus }\end{array}$ & $\begin{array}{l}\text { Dietzia sp., Enterobacter sp., } \\
\text { Klebsiella sp., Proteobacterium, } \\
\text { Bacillus sp. }\end{array}$ \\
\hline 11 & Enterobacter aerogenes & Enterobacter sp., unknown bacteria \\
\hline 12 & Klebsiella pneumoniae & Klebsiella sp. \\
\hline 13 & Group B streptococcus & $\begin{array}{l}\text { Vibrio sp., Escherichia coli, } \\
\text { Burkholderia } \mathrm{sp} .\end{array}$ \\
\hline 14 & Streptococcus agalactiae & $\begin{array}{l}\text { Acinetobacter sp., Klebsiella sp., } \\
\text { Enterobacter sp. }\end{array}$ \\
\hline
\end{tabular}

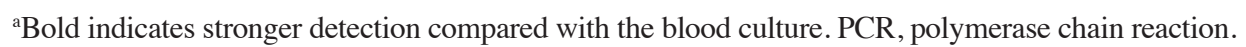

and the sequences were analyzed and blasted on NCBI (http://blast.ncbi.nlm.nih.gov/Blast.cgi?CMD=Web\&PAGE_ TYPE=BlastHome).

Confirmation of the efficiency of the DNA extraction method in spiked samples using the 16S rDNA PCR-DGGE and sequencing method. E. coli and Staphylococcus epidermidis cultures at $1 \times 10^{5} \mathrm{CFU} / \mathrm{ml}(10 \mathrm{ml})$ each were blended in blood samples $(200 \mu \mathrm{l})$ from neonates diagnosed with jaundice to prepare spiked, 'infected' blood samples, in order to imitate the bacterial load in septicemia (4). The bacterial DNA was then extracted following the procedures described above and analyzed by the $16 \mathrm{~S}$ rDNA PCR-DGGE and sequencing method.

Pathogen-specific PCR of blood culture-proven samples. Pathogen-specific PCR was conducted to detect the DNA of the bacteria confirmed by blood culture but not by the 16S rDNA PCR-DGGE and sequencing method. Two patients who were diagnosedwithKlebsiellapneumoniae septicemiawereselected.
The primers for amplification of $K$. pneumoniae were as follows: Forward: 5'-GCGTGGCGGTAGATCTAAGTCATA-3' and reverse: 5'-TTCAGCTCCGCCACAAAGGTA-3'. The PCR conditions and method used to confirm the length of the PCR products were the same as described above.

$16 S$ rDNA PCR-DGGE and sequencing of spiked samples. Enterococcus faecalis, S. epidermidis and Pseudomonas aeruginosa, often observed in septicemia, were used to imitate the situation present in infected blood by a pyrosequencing method. Genomic DNA of each bacterium was extracted as described above. The concentration of the DNA was quantified using NanoDrop 1000 (Nanodrop, Wilmignton, DE, USA) and diluted to $65 \mathrm{ng} / \mu \mathrm{l}$. The DNA of E. faecalis was 5-fold serially diluted (served as less dominant bacteria) and blended with a constant concentration of DNA from the other two bacteria (both served as dominant bacteria). The set of the mixed DNA served as the template and was subjected to a series of $16 \mathrm{~S}$ rDNA PCR amplifications as described previously (10). In addition, the set of diluted DNA of E. faecalis alone served as 


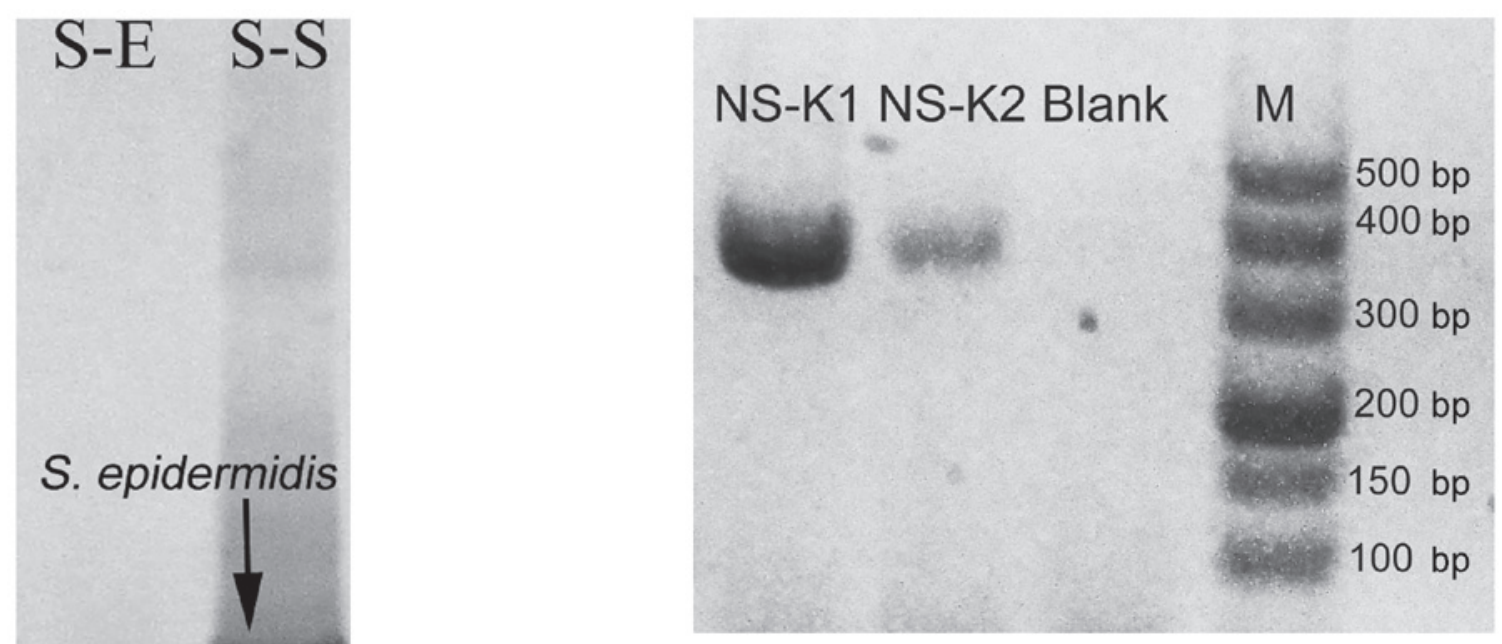

Figure 2. Pathogen-specific PCR of DNA from positive blood culture. Visible bands were observed in NS-K1 and NS-K2 (neonatal septicemia with K. pneumonia) after repeated PCR amplification; the number correspond to patient numbers. PCR, polymerase chain reaction; blank, blank control; $\mathrm{M}$, DNA marker.

The PCR mixture containing $25 \mu$ l Premix Taq (Takara Bio Inc.), $1 \mu \mathrm{l}$ of each primer $(10 \mu \mathrm{M}), 1 \mu \mathrm{l}$ diluted DNA of E. faecalis, or $3 \mu \mathrm{l}$ (mixed DNA with $1 \mu \mathrm{l}$ of each bacterial DNA) of bacterial DNA was adjusted to a final volume of $50 \mu \mathrm{l}$ with sterile water. The PCR products were then analyzed by the DGGE and sequencing method as described above.

\section{Results}

Blood culture. From January to May 2012, 60 neonates who were suspected of neonatal septicemia were enrolled in the present study. Positive blood culture results occurring $>72 \mathrm{~h}$ after birth were reported for 14 of these 60 neonates (Table I). Of these 14 neonates with positive blood culture, 12 neonates were diagnosed with mono-bacterial infection and 2 neonates were confirmed to be infected by two species of bacteria.

Bacterial spectrum screened by molecular methods. The sequencing results showed diverse bacterial species in the blood samples, the majority of which were not detected by blood culture (Table I). Only in five cases did the sequencing results match partly or wholly with the blood culture results. One of these five patients was diagnosed with $K$. pneumoniae bloodstream infection, which was confirmed by molecular methods and blood culture. In the other four of these five cases, the molecular method detected a more complex bacterial spectrum, which contained the blood culture proven bacteria (Table I). In the other 9 cases, blood culture failed to detect bacteria, such as Neisseria sp.,Moraxella sp., that were detected by the 16S rDNA PCR-DGGE and sequencing method. In addition, the 16S rDNA PCR-DGGE and sequencing method

Figure 1. Denaturing gradient gel electrophoresis fingerprint after DNA extraction and $16 \mathrm{~S}$ rDNA polymerase chain reaction of spiked blood samples. S-E, blood sample spiked with E. coli; S-S, blood sample spiked with S.epidermidis. 

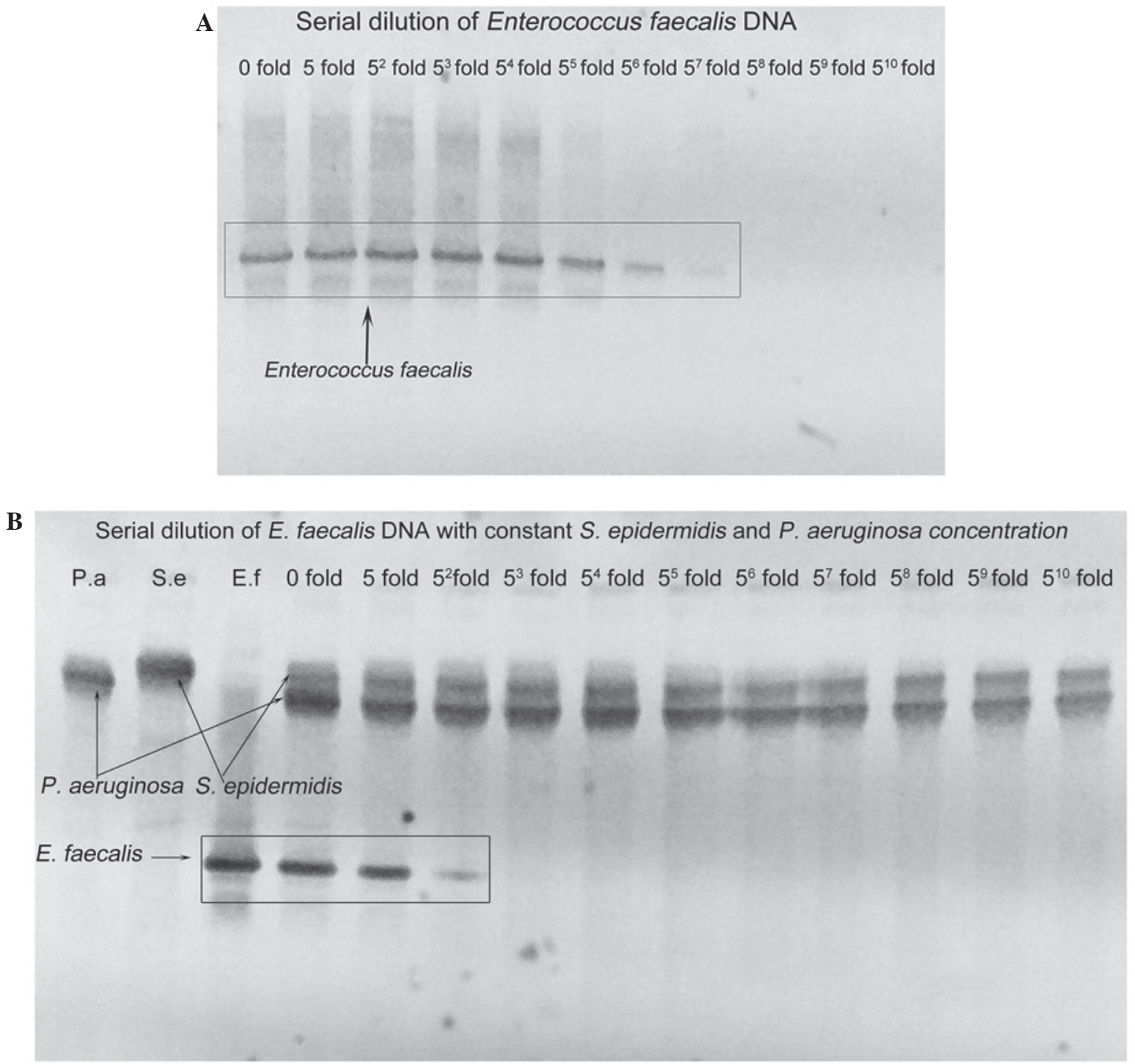

Figure 3. Competitive inhibitory effect in 16S rDNA PCR-DGGE. (A) Detection limit of PCR-DGGE when E. faecalis DNA was amplified alone. The genomic DNA of E. faecalis was serially diluted 5-fold, and a visible DNA band was observed even at a 57-fold dilution. (B) Detection limit of PCR-DGGE when E. faecalis DNA was amplified together with $S$. epidermidis and P. aeruginosa DNA. The genomic E. faecalis DNA was serially diluted by 5 -fold, while the concentrations of DNA from S. epidermidis and P. aeruginosa remained constant. The bands corresponding to PCR amplification of E. faecalis DNA disappeared when the DNA template was diluted by 53 -fold. P. a, P. aeruginosa; S.e, S. epidermidis; E.f, E. faecalis. The numbers indicate fold dilution. PCR-DGGE, polymerase chain reaction-denaturing gradient gel electrophoresis.

were as follows. Firstly, efficiency of the DNA extraction method was tested. Then pathogen-specific PCR was applied to confirm the existence of culture-proven bacterial DNA in the sample DNA solutions. Thirdly, spiked samples were made to imitate the infection revealed by $16 \mathrm{~S}$ rDNA PCR-DGGE and sequencing (presence of 'culture-proven pathogen' bacteria with other bacteria detected by molecular method). The hypothesis that the molecular method-proven bacterial DNA could interfere with the detection of blood culture-proven bacteria was tested in these spiked blood samples by the $16 \mathrm{~S}$ rDNA PCR-DGGE and sequencing method as described in the materials and methods.

Efficiency of the DNA extraction method. The results of the PCR-DGGE and sequencing method for the spiked 'infected' blood samples demonstrated that the DNA of the corresponding bacteria in blood was successfully isolated. The bands on the polyacrylamide gel of the DGGE were identical to those of E. coli and S. epidermidis, which were confirmed by subsequent sequencing (Fig. 1).

Detection of blood culture-proven pathogens by pathogen-specific PCR. No visible band was found on the gels of two culture-proven cases after PCR-agarose gel electrophoresis. Hence, a second PCR amplification of the products from the first amplification was performed. After the second amplification, the target gene of K. pneumoniae was observed on the agarose gel (Fig. 2).

Competitive inhibitory effect of $16 S$ rDNA PCR-DGGE. The detection limits of 16S rDNA PCR-DGGE for a single certain species of bacterial DNA versus mixed species of bacterial DNA (mixture of other bacterial DNA with this certain species of bacterial DNA) were completely different 
with a higher sensitivity in detecting this certain species of bacterial DNA in the spiked samples which were free of other bacterial DNA (Fig. 3A and B). When the E. faecalis DNA was amplified alone even at a $1 \times 5^{7}$-fold dilution, the faint band amplified from $E$. faecalis DNA was still observed (Fig. 3A). When the DNAs of the other two species of bacteria were introduced, no band was observed for E. faecalis DNA even at dilution by $1 \times 5^{3}$-fold (Fig. 3B). The detection limit of E. faecalis was different under the above two situations where the amount of E. faecalis DNA and 16S rDNA were identical throughout, indicating a possible influence of the introduced bacterial DNA on detecting the E. faecalis DNA. As the amplifying condition of $16 \mathrm{~S}$ rDNA PCR was consistent, the introduced bacterial DNA caused reduced capability in amplifying $E$. faecalis DNA. There was lower sensitivity of $16 \mathrm{~S}$ rDNA PCR in detecting the same copies of E. faecalis DNA when other bacterial DNA was introduced, compared with detecting the E. faecalis DNA in the samples containing E.faecalis DNA alone. This suggests a competitive inhibitory effect of other bacterial DNA on the $E$. faecalis DNA during the 16S rDNA PCR amplification.

\section{Discussion}

The recognition of pathogens in the blood is a crucial aspect in the management of neonates with LOS (6). Although blood culture is regarded as a gold standard in the clinic, there is a requirement for a more rapid and sensitive strategy to detect the bacteria in the blood (5).

In the present study, although a broader bacterial spectrum was demonstrated by the $16 \mathrm{~S}$ rDNA PCR-DGGE and sequencing method as compared with blood culture, it failed to detect culture-proven bacteria in 9 of the 14 blood culture-positive cases, indicating its poor correlation with blood culture.

The 16S rDNA PCR technique involves broad-range PCR amplification of the $16 \mathrm{~S}$ rDNA regions of different bacterial species and has been reported by Muyzer et al (11) to be sensitive enough to detect one species of bacterium in a bacterial community when the bacterium constitutes $>1 \%$. To determine whether the sensitivity is responsible for the failure of $16 \mathrm{~S}$ rDNA PCR in the diagnosis of certain culture-proven cases of septicemia, pathogen-specific PCR was used in the samples in which blood culture-proven bacteria failed to be detected by $16 \mathrm{~S}$ rDNA PCR-DGGE and sequencing method. Using this procedure the present study aimed to confirm whether the DNA of culture-proven bacteria was successfully extracted and existed in the sample DNA solutions. The results of pathogen-specific PCR demonstrated the presence of a low amount (only detected after the second amplification) culture-proven bacterial DNA in the sample DNA solutions. Given the fact that the 16S rDNA PCR used in the present study also went through the second PCR amplification in nested-PCR, which is similar to the second PCR amplification in the pathogen-specific PCR, 16S rDNA PCR had the same capability in detecting these trace amounts of bacterial DNA. The low load of culture-proven bacterial DNA may not account for the discrepancy between the 16S rDNA PCR and pathogen-specific PCR methods. The only difference between these two PCR methods is in that pathogen-specific PCR primers target a specific species of bacterial DNA, but $16 \mathrm{~S}$ rDNA PCR primers target the whole bacterial spectrum of DNA in the samples. To investigate whether the detection of blood culture-proven bacterial DNA (such as Klebsiella pneumonia) interfered with the molecular method-proven bacterial DNA (such as Neisseria sp., Moraxella sp.) in the 16S rDNA PCR amplification among the patients with poor correlation between the two detection methods, spiked samples were used to imitate the situation (presence of other bacterial DNA with blood culture-proven bacterial DNA) and performed $16 \mathrm{~S}$ rDNA PCR-DGGE.

The results obtained from the test on spiked samples in the present study supported the above hypothesis and demonstrated a competitive inhibitory effect, an unequal amplification of different bacterial DNAs in the 16S rDNA PCR. The 16S rDNA PCR-DGGE has a higher sensitivity in detecting the 'pathogen' bacterial DNA when the spiked samples were free of other bacterial 'infection'. However, the introduction of other bacterial DNAs interferes with the detection of the 'pathogen' bacteria by the $16 \mathrm{~S}$ rDNA PCR-DGGE method.

Our findings demonstrate that the $16 \mathrm{~S}$ rDNA PCR based molecular methods may cause bias in screening bacteria in LOS due to the competitive inhibitory effect. A previous study conducted by Muyzer et al (11) does not address the exact reason for the limited sensitivity of $16 \mathrm{~S}$ rDNA PCR-DGGE. The present study demonstrates that the limited sensitivity of $16 \mathrm{~S}$ rDNA PCR-DGGE in detecting bacteria which constitutes $<1 \%$ of the whole bacterial community may be attributed to an unequal PCR amplification among the bacteria in the bacterial community. For this reason, any practice which leads to a change in the constitution of the bacterial community should be noticed and avoided when applying the $16 \mathrm{~S}$ rDNA PCR based molecular method. For instance, numerous attempts have been made to enhance the sensitivity of 16S rDNA PCR, including pre-culture of blood (incubation before bacterial DNA extraction) to amplify the amount of the bacteria in the blood samples (12-14). Although pre-culture is useful for enhancing the detection limit of $16 \mathrm{~S}$ rDNA PCR, it can induce a competitive inhibitory effect in 16S rDNA PCR amplification of easy-to-grow bacteria and fastidious/uncultivable bacteria under certain culture conditions. Therefore, pre-culture adversely affects the ability to detect fastidious/uncultivable bacteria with the 16S rDNA PCR based molecular methods.

Limitations of the present study include a small sample size and lack of more accurate quantitative methods. The competitive inhibitory effect was an obstacle to the application of $16 \mathrm{~S}$ rDNA PCR in the diagnosis of neonatal LOS. Thus, the present study did not attempt to investigate its use in a large-scale neonatal population.

Overall, this preliminary investigation focused on the efficiency of the 16S rDNA PCR-DGGE and sequencing method in the diagnosis of neonatal LOS. It was demonstrated that a competitive inhibitory effect caused a bias in 16S rDNA PCR amplification to screen the bacterial spectrum of neonatal septicemia. To obtain a higher efficiency of 16S rDNA PCR-DGGE and sequencing for the diagnosis of LOS, protocols aiming to overcome the competitive inhibitory effect in $16 \mathrm{~S}$ rDNA PCR amplification require development in the future. 


\section{Acknowledgements}

The authors would like to thank Mr. Yu He and Mr. Hongdong Li for helpful discussion of the manuscript. This manuscript has been edited and proofread by Medjaden Bioscience Limited (Hong Kong, China). This study was supported by the National Natural Science Foundation of China (grant no. 81370744), Doctoral Degree Funding from Chinese Ministry of Education (grant no. 20135503110009), State key clinic discipline project (grant no. 2011-873) and the subproject of National Science \& Technology Pillar Program during the 12th Five-year Plan Period in China (grant no. 2012BAI04B05).

\section{References}

1. Tsai M-H, Hsu JF, Chu SM, Lien R, Huang HR, Chiang MC, Fu RH, Lee CW and Huang YC: Incidence, clinical characteristics and risk factors for adverse outcome in neonates with late-onset sepsis. Pediatr Infect Dis J 33: e7-e13, 2014.

2. Stoll BJ, Hansen N, Fanaroff AA, Wright LL, Carlo WA, Ehrenkranz RA, Lemons JA, Donovan EF, Stark AR, Tyson JE, et al: Late-onset sepsis in very low birth weight neonates: The experience of the NICHD neonatal research network. Pediatrics 110: 285-291, 2002.

3. Rubin LG, Sánchez PJ, Siegel J, Levine G, Saiman L and Jarvis WR; Pediatric Prevention Network: Evaluation and treatment of neonates with suspected late-onset sepsis: A survey of neonatologists' practices. Pediatrics 110: e42, 2002.

4. Paolucci M, Landini MP and Sambri V: Conventional and molecular techniques for the early diagnosis of bacteraemia. Int J Antimicrob Agents 36 (Suppl 2): S6-S16, 2010.
5. Peters RP, van Agtmael MA, Danner SA, Savelkoul PH and Vandenbroucke-Grauls CM: New developments in the diagnosis of blood stream infections. Lancet Infect Dis 4: 751-760, 2004.

6. Mancini N, Carletti S, Ghidoli N, Cichero P, Ossi CM, Ieri R, Poli E, Burioni R and Clementi M: Molecular diagnosis of polymicrobial sepsis. J Clin Microbiol 47: 1274-1275, 2009.

7. Sontakke S, Cadenas MB, Maggi RG, Diniz PP and Breitschwerdt EB: Use of broad range16S rDNA PCR in clinical microbiology. J Microbiol Methods 76: 217-225, 2009.

8. Ley BE, Linton CJ, Bennett DM, Jalal H, Foot AB and Millar MR: Detection of bacteraemia in patients with fever and neutropenia using $16 \mathrm{~S}$ rRNA gene amplification by polymerase chain reaction. Eur J Clin Microbiol Infect Dis 17: 247-253, 1998.

9. Ng PC, Cheng SH, Chui KM, Fok TF, Wong MY, Wong W, Wong RP and Cheung KL: Diagnosis of late onset neonatal sepsis with cytokines, adhesion molecule and C-reactive protein in preterm very low birthweight infants. Arch Dis Child Fetal Neonatal Ed 77: F221-F227, 1997.

10. Yu Z and Morrison M: Comparisons of different hypervariable regions of rrs genes for use in fingerprinting of microbial communities by PCR-denaturing gradient gel electrophoresis. Appl Environ Microbiol 70: 4800-4806, 2004.

11. Muyzer G, de Waal EC and Uitterlinden AG: Profiling of complex microbial populations by denaturing gradient gel electrophoresis analysis of polymerase chain reaction-amplified genes coding for 16S rRNA. Appl Environ Microbiol 59: 695-700, 1993.

12. Pammi M, Flores A, Leeflang $M$ and Versalovic J: Molecular assays in the diagnosis of neonatal sepsis: A systematic review and meta-analysis. Pediatrics 128: e973-e985, 2011.

13. Jordan JA, Butchko AR and Durso MB: Use of pyrosequencing of $16 \mathrm{~S}$ rRNA fragments to differentiate between bacteria responsible for neonatal sepsis. J Mol Diagn 7: 105-110, 2005.

14. Jordan JA and Durso MB: Comparison of $16 \mathrm{~S}$ rRNA gene PCR and BACTEC 9240 for detection of neonatal bacteremia. J Clin Microbiol 38: 2574-2578, 2000. 